\title{
The Effect of Fabrication Method on Passive UHF RFID Tag Performance
}

\author{
Toni Björninen, ${ }^{1}$ Sari Merilampi, ${ }^{2}$ Leena Ukkonen, ${ }^{1}$ Lauri Sydänheimo, ${ }^{1}$ \\ and Pekka Ruuskanen ${ }^{2}$ \\ ${ }^{1}$ Rauma Research Unit, Institute of Electronics, Tampere University of Technology, Kalliokatu 2, 26100 Rauma, Finland
${ }^{2}$ Department of Electronics, Tampere University of Technology-Pori, Pohjoisranta 11 A, 28100 Pori, Finland
}

Correspondence should be addressed to Toni Björninen, toni.bjorninen@tut.fi

Received 22 October 2008; Revised 11 February 2009; Accepted 7 May 2009

Recommended by You Chung Chung

In passive Radio Frequency Identification (RFID), transponders or tags are used to label objects to be identified. In this study passive tag antennas were produced using etching, screen-printing, and gravure printing methods. The threshold and backscattered signal strengths of the tags were measured to determine the effect of different manufacturing methods on the tags' performance. Conductivity, skin depth, thickness, and the quality of the conducting layer have a major effect on tag performance. Each manufacturing method sets its own boundary conditions on the processibility of the high quality conduction layer and such conditions need to be considered in tag design. Tag design also affects the manufacturing parameters used in the different techniques. The results of the study show that each of the studied fabrication methods can be used to manufacture reliable RFID tags.

Copyright (C 2009 Toni Björninen et al. This is an open access article distributed under the Creative Commons Attribution License, which permits unrestricted use, distribution, and reproduction in any medium, provided the original work is properly cited.

\section{Introduction}

The use of passive UHF RFID systems is increasing rapidly in numerous applications. Globally, the allowed frequencies for UHF RFID range from $840 \mathrm{MHz}$ to $955 \mathrm{MHz}$, depending on the local regulations [1].

Antennas are integrated into a variety of applications such as product packaging and clothing. Currently copper is the most commonly used conductor in tag antennas and the etching is the most widely used manufacturing technique to produce the conductive patterns. However, the cost of antennas is a crucial factor in the mass production of antennas and there is an increasing need to develop new manufacturing techniques to enable the manufacturing of RFID tags on complicated curved surfaces at economically competitive cost. This can be achieved by applying new economical manufacturing methods to produce the antenna structures. Printing techniques may provide a new and fast way to do this. In printed electronics silver particles are often used to form the conductive layer, and therefore it is important to optimize the amount of silver and the thickness of the conductive layer. At the same time it is also important that the ink layer is thick enough to achieve low ohmic losses. However, in RFID systems thin conducting layers are preferred to maintain low manufacturing costs.

The penetration depth and ohmic losses of the conductive layer set the boundary condition for the manufacturing methods and manufacturing parameters such as the amount of silver and the thickness of the layer. One factor controlling the thickness of the conductive layer is the skin effect or penetration depth. At high frequencies, like UHF, the current density is packed in the region near the surface of a good conductor. This is called the skin effect. Skin depth or penetration depth is defined as the depth below the surface of the conductor at which the amplitude of the incident electric field decays to 0.37 percent of the amplitude at the surface of the conductor.

For good conductors, the penetration depth has the wellknown approximate expression

$$
\delta=\frac{1}{\sqrt{\pi f \mu \sigma}},
$$


where $f$ is the frequency, $\mu$ is the permeability $\left(\sim \mu_{0}\right)$, and $\sigma$ is the conductivity of the conductor material [2].

RFID tags can be made in various ways. In this study, etching, screen, and gravure printing techniques were compared and used to produce RFID antennas. Etching, which is the traditional way of making the conductors, was used as a reference technique for the printing techniques. It is a well-known method and is widely used to produce conductive patterns in the electronics industry. However, printing techniques have several advantages over the etching technique. Printing is a fast and environmentally friendly process; less hazardous chemicals are needed and printing can be used to produce $3 \mathrm{D}$ conductive patterns in an economically competitive way.

In etching process, a thin copper or aluminum foil on a substrate material is etched into the form of the designed antenna pattern. In an industrial process the IC-chip can be connected to the antenna, for example, by reflow soldering. In case the antenna is etched on a special substrate, which does not tolerate reflow process or the antenna pattern is printed, conductive adhesives can be used. Usually the antenna structure is also shielded with a thin layer of plastic to improve its endurance. In etching process, the substrate material must tolerate the chemicals used in the etching process, and this restricts the choice of substrate material. Polyethelene Terephthalate (PET) is commonly used as an antenna substrate material. The thickness of the foils is typically $18 \mu \mathrm{m}$ or $35 \mu \mathrm{m}$ for copper and $9 \mu \mathrm{m}$ for aluminum. A typical etchant is ferricloride, which corrodes both copper and aluminum. The thickness of the conductor metal has an influence on the etching process, tag antenna performance, and also on the manufacturing costs [3-5].

In the electronics industry there is increased use of a variety of printing techniques to produce electrical conductors. The main components used in a printed RFID antenna are conductive ink and a substrate. Conductive inks consist of a polymer matrix, conductive fillers, and solvents. Silver particles are commonly used as the conductive filler material. Paper, plastic, and fabric can be used as the substrate material. The printing techniques offer a new way to transfer electronics circuits onto several materials, such as paper, plastic, and fabric. Different printing technologies require different ink characteristics $[3,6]$.

Screen printing is commonly used in electronic manufacturing. The conductive ink is pressed through a stencil onto the substrate with a squeegee. The stencil consists of the frame and a fabric mesh of threads. The advantage of this technique is that it enables very thin printing and also very thick films (from $0.02 \mu \mathrm{m}$ to $100 \mu \mathrm{m}$ according to [5]). The thickness of the ink layer is determined by the screen and the printing parameters. One possible constraint with screen printing is resolution, which reaches a maximum of about 50 lines per centimetre $[4,6,7]$.

Gravure printing is a technique, which uses an engraved cylinder to transfer the figure to the substrate. The engraved figure on the cylinder consists of gravure cells which hold the ink while transferring the figure [8]. Gravure printing is used for very long runs. It is a fast technique and enables mass production. The thickness of the printed figure depends

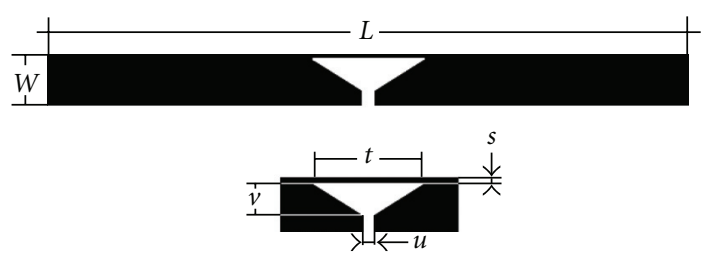

FIgURE 1: Shape and dimensions of the printed tag design.

on the engravings on the gravure cylinder but process parameters such as printing speed and pressure also have an effect on the figure. In article [9] 20-60 $\mu \mathrm{m}$ gravure cells produced a $4-7 \mu \mathrm{m}$ ink layer. The substrate must be flexible in gravure printing because of the pressure needed in figure transfer. The resolution that can be achieved with gravure printing is 100 lines per centimeter according to [6].

\section{Experimental Arrangements}

2.1. Simulations. Input impedance at the antenna terminals depends on the geometry and material of the antenna and all other proximate materials. By definition, the radiation resistance of an antenna is the resistance, which relates the radiated power to the current at the antenna terminals. Similarly antenna loss resistance relates the terminal current to the difference of the accepted power and radiated power. The total resistance at the antenna input is the sum of these two resistances and its input reactance is related to the reactive power in the near field zone [10]. Antenna impedance is therefore strongly dependent on the antenna radiation and near-field coupling, which makes it a complicated parameter as a whole. Nevertheless antenna impedance is an important parameter in antenna design, since the power delivery to the load depends crucially on the impedance matching between the antenna and load impedances. In this study Ansoft's High Frequency Structure Simulator (HFSS) was used to design complex conjugate match between the antenna and load impedances.

Tag antennas used in the present study are rectangular short dipole tags equipped with a triangular matching loop. This matching technique is a slightly modified embedded T-matching, which is discussed in [11]. The embedded Tmatching with a rectangular gap is successfully used for tag antenna matching, for example, in [12], but in the simulations we found the triangular gap better suited for our design.

Figure 1 shows the geometry of the screen-printed and gravure-printed tags and the dimensions of the designs are gathered in Table 1.

From the simulated antenna impedance we calculated the Power Reflection Coefficient (PRC) [12], which describes the quality of the complex conjugate match. According to the calculated PRC, the dimensions of the matching loop were adjusted to tune the screen-printed tag and the etched tag for optimal operation at $866 \mathrm{MHz}$. The IC-chip for both designs is Alien Higgs H2 [13]. It is provided by the manufacturer in a strap, which is readily attached to antenna structure. 
TABle 1: Dimensions of different antenna designs.

\begin{tabular}{lcc}
\hline Dimension $[\mathrm{mm}]$ & Screen- and gravure-printed & Etched \\
\hline$W$ & 8 & 9 \\
$L$ & 97 & 100 \\
$s$ & 17 & 15.6 \\
$t$ & 0.5 & 0.5 \\
$u$ & 2 & 2 \\
$v$ & 5 & 6 \\
\hline
\end{tabular}

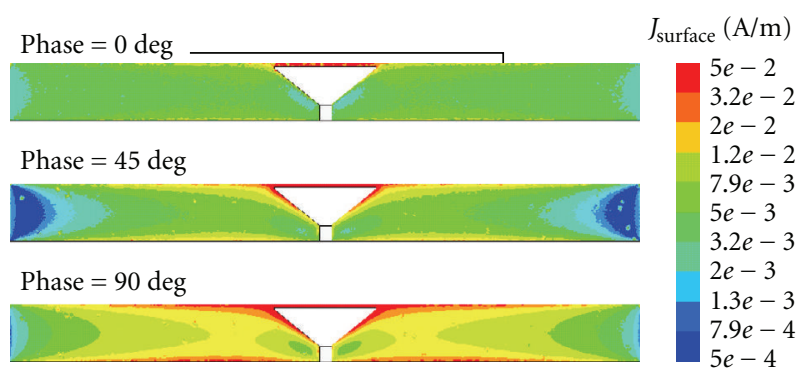

Figure 2: Simulated surface current density in the antenna structure under a plane wave incidence with different phases of incident wave.

In our study we have used impedance $Z_{c}=(17-j 137) \Omega$ to model the strap at $866 \mathrm{MHz}$, in order to maximize power transfer at this frequency, but in reality the strap impedance changes with frequency. In addition the dipole antenna is not designed for operation in the Global UHF RFID frequency range, and therefore we have limited our study around the European RFID frequencies.

In practice the nonuniform distribution of the ink becomes apparent when the printed layer is very thin, as in the gravure-printed tag. This effect is particularly evident in narrow traces, where the current density is high, such as in the matching loop of the manufactured tag (see Figure 11). The high current density in this part is shown in Figure 2, which illustrates induced current density in the structure under a normal plane wave incidence with amplitude $1 \mathrm{~V} / \mathrm{m}$.

The effect of the non-ideal print quality in this part the antenna was modelled afterwards by reducing the nominal trace width by $30 \%$ to account for the effect of the ragged edge of the actual printed conductor. This makes it possible to predict the frequency shift in the measurement results (see Figures 5 and 6 ).

2.2. Tag Fabrication. The RFID tags shown in Figure 1 were manufactured by screen printing, gravure printing and etching methods. PET was used as the substrate material for all prototype tags. The thickness of the PET substrate was $75 \mu \mathrm{m}$ when printing was used for tag fabrication and $50 \mu \mathrm{m}$ when etching was used for tag fabrication.

Screen-printed tags were printed with screen printable polymeric silver ink. The characteristics of the screen printing ink are presented in Table 2.

Gravure-printed tags were printed using polymeric rotogravure ink. The characteristics of the gravure printable ink are presented in Table 3.
TABLE 2: Characteristics of screen printable ink.

\begin{tabular}{lccc}
\hline $\begin{array}{l}\text { Manufacturer's } \\
\text { description }\end{array}$ & $\begin{array}{c}\text { Curing } \\
\text { conditions } \\
\left({ }^{\circ} \mathrm{C}, \mathrm{min}\right)\end{array}$ & $\begin{array}{c}\text { Viscosity } \\
(\mathrm{P})\end{array}$ & $\begin{array}{c}\text { Conductivity } \\
(\mathrm{MS} / \mathrm{m})\end{array}$ \\
\hline $\begin{array}{l}\text { Single component silver } \\
\text { ink consisting of } \\
\text { polyester resin and silver } \\
\text { particles. }\end{array}$ & 120,20 & $200-300$ & 1.25 \\
\hline
\end{tabular}

TABLE 3: Characteristics of gravure printable ink.

\begin{tabular}{lccc}
\hline $\begin{array}{l}\text { Manufacturer's } \\
\text { description }\end{array}$ & $\begin{array}{c}\text { Curing } \\
\text { conditions } \\
\left({ }^{\circ} \mathrm{C}, \mathrm{min}\right)\end{array}$ & $\begin{array}{c}\text { Viscosity } \\
(\mathrm{P})\end{array}$ & $\begin{array}{c}\text { Conductivity } \\
(\mathrm{MS} / \mathrm{m})\end{array}$ \\
\hline $\begin{array}{l}\text { Silver pigment in a } \\
\text { thermoplastic resin for }\end{array}$ & 120,20 & 40 & 4 \\
$\begin{array}{l}\text { flexographic or } \\
\text { rotogravure printing } \\
\text { techniques. }\end{array}$ & & & \\
\hline
\end{tabular}

TABLE 4: The printed samples.

\begin{tabular}{lllc}
\hline Sample & Symbol & Printing equipment & $\begin{array}{c}\text { Number of ink } \\
\text { layers }\end{array}$ \\
\hline Sample 1 & Screen & $\begin{array}{l}\text { Screen (mesh/width of } \\
\text { thread: 124/27) }\end{array}$ & 2 \\
Sample 2 & Gravure & $\begin{array}{l}\text { Gravure cylinder (Depth } \\
\text { of cells: } 60 \mu \mathrm{m})\end{array}$ & 1 \\
\hline
\end{tabular}

Information on the printed samples is presented in Table 4. Screen-printed samples were produced by printing two layers of ink. The ink layer was cured after the second printing. Rotogravure silver ink was diluted with nPropylacetate before gravure printing.

Copper tags were produced by etching. Copper of $20 \mu \mathrm{m}$ thickness on $50 \mu \mathrm{m}$ thick PET foil were used as tag materials. The negative photosensitive resist foil was laminated on the copper and light exposure was performed under UV light. The resist was developed with $1.2 \% \mathrm{Na}_{2} \mathrm{CO}_{3}$ and $32 \% \mathrm{FeCl}_{3}$ was used for the etching. The resist was stripped with $3 \%$ $\mathrm{NaOH}$.

\section{Measurement Equipments and Procedures}

3.1. Thickness of the Printed Tags. The thickness of the conductive layer was measured before antenna measurements using software connected to an optical microscope. The thickness values are an average value of 20 different measurement points in the middle of the cross-section, which is marked Figure 3 by the red line. Location was selected by visual inspection to represent a typical distribution of the printed ink layer.

The copper layer is more uniform than the printed layers and has a thickness of $20 \mu \mathrm{m}$ as reported by the copper foil manufacturer.

3.2. Antenna Measurements. Two different quantities, threshold power and backscattered signal power, were measured 


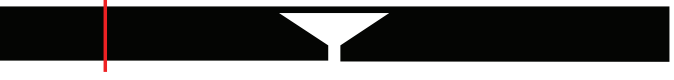

Figure 3: Location of the cross-section for the thickness measurement.

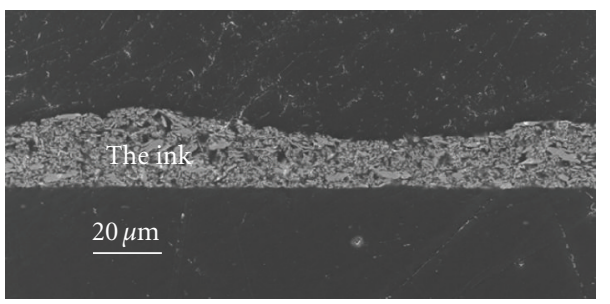

FIGURE 4: Scanning electron micrograph of a cross-section of a screen-printed sample.

to study the performance of the fabricated tags. All the measurements were made with Voyantic Tagformance measurement unit [14]. The distance for threshold and backscatter measurements was $1.5 \mathrm{~m}$.

Threshold power is the minimum sufficient power to activate the IC-chip. Measurement of threshold power was performed by increasing the transmitted power until the tag can respond to the reader's query command. The effect of path loss and tag antenna gain can be approximated by using a calibration tag, with known properties. Calibration tag is provided by the manufacturer of the measurement device, as part of the measurement system. Decisive factors for the threshold power are the quality of the conjugate match between the antenna and the IC-chip, and the sensitivity of the IC-chip.

Backscattered signal power is a critical factor for the performance of an RFID tag. Assuming that the tag has sufficient power to activate the IC-chip, backscattered signal power together with the reader's sensitivity are the key factors for the tag-reader read range and reliability of the reception.

In addition to the above-described performance parameters an intuitive way to evaluate the performance of an RFID tag is the detection range. It is the maximum distance at which a valid response from the tag can be received. In a passive RFID system the detection range is typically limited by the forward link operation and more specifically the IC-chip's sensitivity. Detection range also depends on the radiation patterns and polarization of the reader antenna and the tag and the propagation channel. The detection range patterns in two orthogonal planes were measured for the fabricated tags. In this measurement the polarizations of the reader and tag antenna were matched and measurement was done with $2 \mathrm{~W}$ transmitted ERP-power, which is the maximum allowed transmitted power in the European RFID band.

\section{Results and Discussion}

4.1. Thickness of the Printed Tags. When printing is used to produce prototype tag antennas there are thickness
TABLE 5: Thickness measurement statistics for the printed tags.

\begin{tabular}{lcccc}
\hline Sample & Average $[\mu \mathrm{m}]$ & $\operatorname{Min}[\mu \mathrm{m}]$ & $\operatorname{Max}[\mu \mathrm{m}]$ & $\begin{array}{c}\text { Standard } \\
\text { deviation }[\mu \mathrm{m}]\end{array}$ \\
\hline Screen & 21.5 & 16.8 & 26.0 & 2.5 \\
Gravure & 3.8 & 1.6 & 5.4 & 0.8 \\
\hline
\end{tabular}

variations in the ink layer. The thickness measurement results of the printed samples are presented in Table 5. The variation in the ink layer after screen printing can be seen in Figure 4 . The variations in thickness make the modeling challenging, but a good estimate of the ink layer thickness can still be found by multiple measurements.

4.2. The Antenna Measurements. Simulated antenna impedances for different antennas are shown in Figure 5. Corresponding PRC's are presented in Figure 6, where the dashed blue and black curves correspond to situations where strap reactance would be $3 \Omega$ less or $3 \Omega$ more than the nominal value, respectively. Figure 7 shows the simulated PRC's for different antennas with nominal strap impedance. For gravure-printed tag two simulations were performed: "nominal" and "realized". The former term refers to nominal design and the latter to the simulation where the effect of the nonuniform distribution of the conductive ink was taken into account.

Measurement results for threshold power and backscattered signal power are presented in Figures 8 and 9, respectively.

Simulation results in Figure 5 predict that the nominal antenna resistances and reactances are within $5 \Omega$ from each at the studied frequencies. Simulated resistance of the realized gravure printed tag is slightly increased from the nominal one, but it is still within $5 \Omega$ from the simulated resistance of the other tags. Its reactance, however, differs significantly from the simulated reactances of the tags.

In reality accurate knowledge of the chip impedance is important for realization of impedance matching at the intended frequency. To account for uncertainties in the strap impedance, due to parasitics of the chip package and attachment to the antenna, $\pm 3 \Omega$ variations from nominal reactance was studied in Figure 6. Study was performed for chip reactance, since in simulations it was found to have stronger effect on the PRC's frequency behavior. According to this simulation $\pm 3 \Omega$ change in chip reactance may shift the operation frequency around $10 \mathrm{MHz}$ from the nominal case.

Simulation results in Figure 7 were obtained with nominal strap impedance and one can see that all the designs are reasonably well tuned for operation at $866 \mathrm{MHz}$. It should be noted that conductivity and thickness of the conducting layer affect the radiation efficiency. The measured threshold power curves in Figure 8 therefore appear in a different order to the simulated PRC's in Figure 7. However, the simulation results can be used to predict fairly accurately the operating frequencies corresponding to the minimum threshold powers as well as their mutual order; only the measured operation frequency of the screen-printed tag 


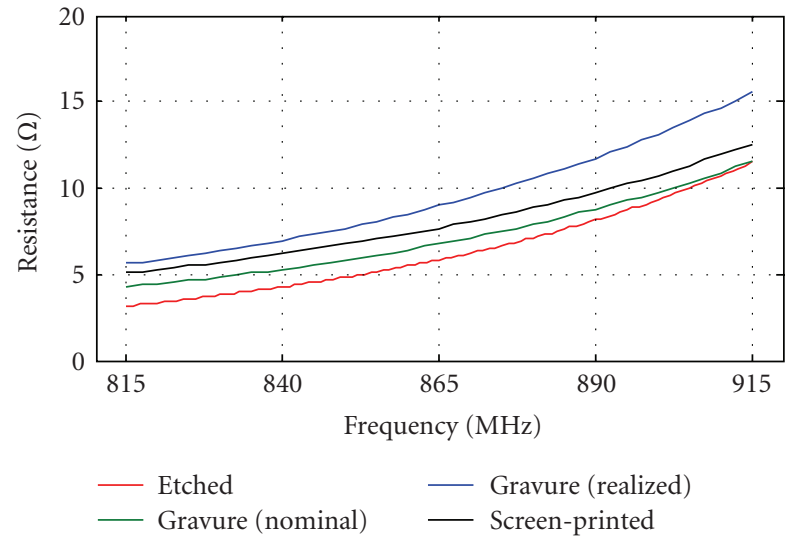

(a)

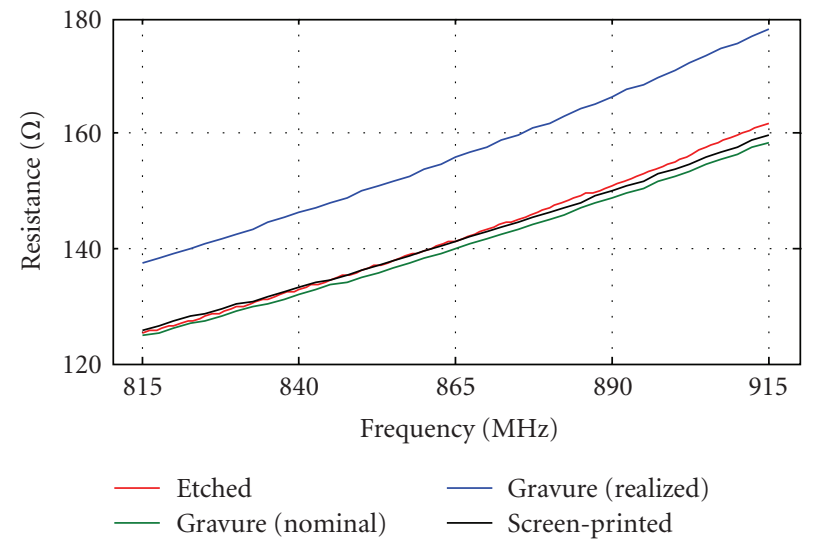

(b)

FIGURE 5: Simulated antenna impedances.

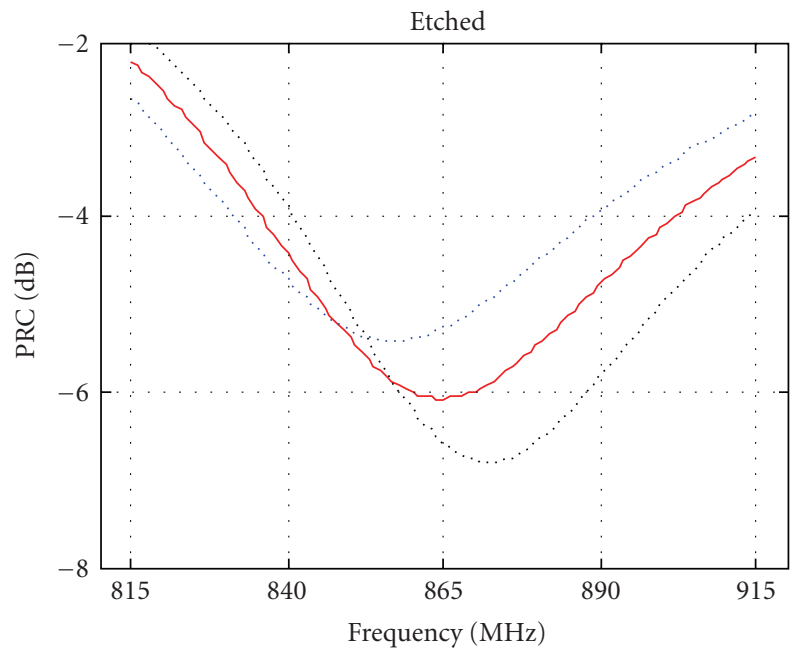

(a)

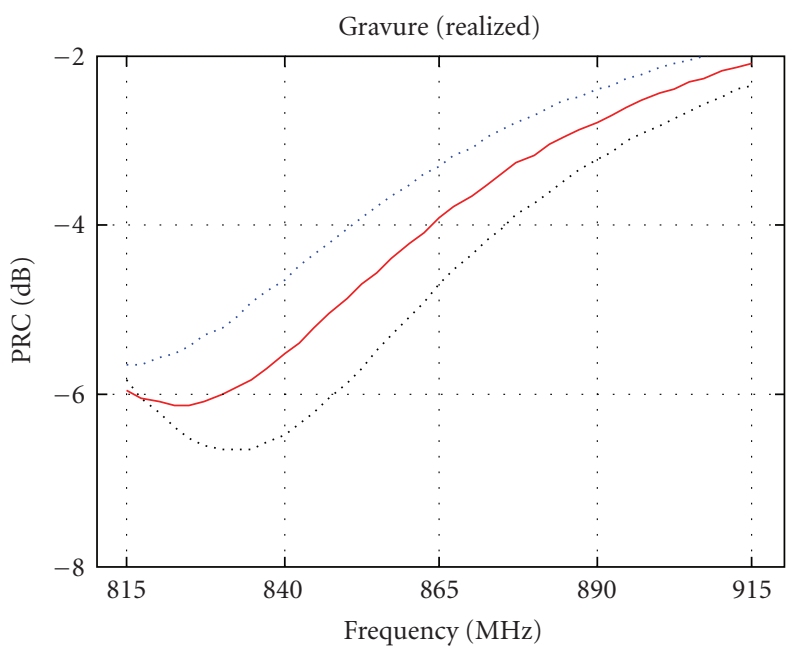

(c)

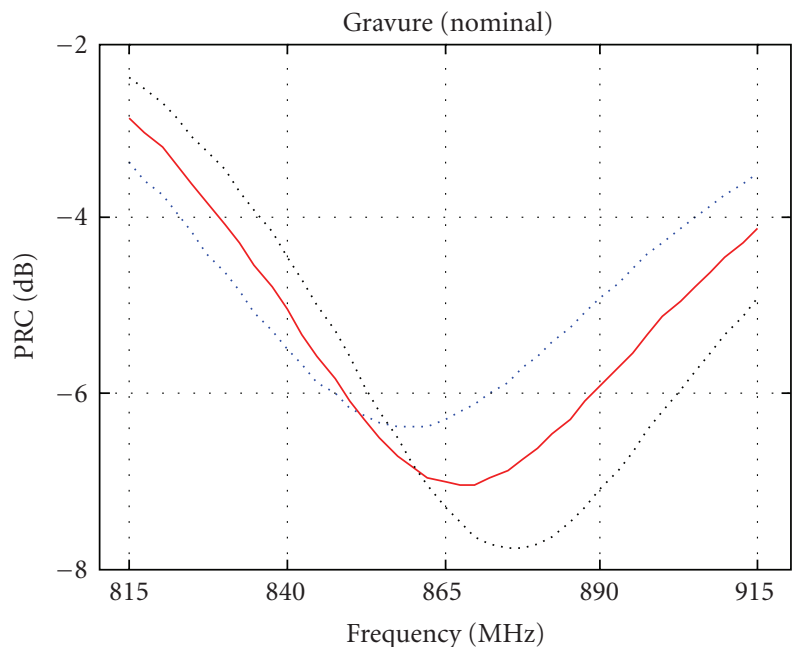

(b)

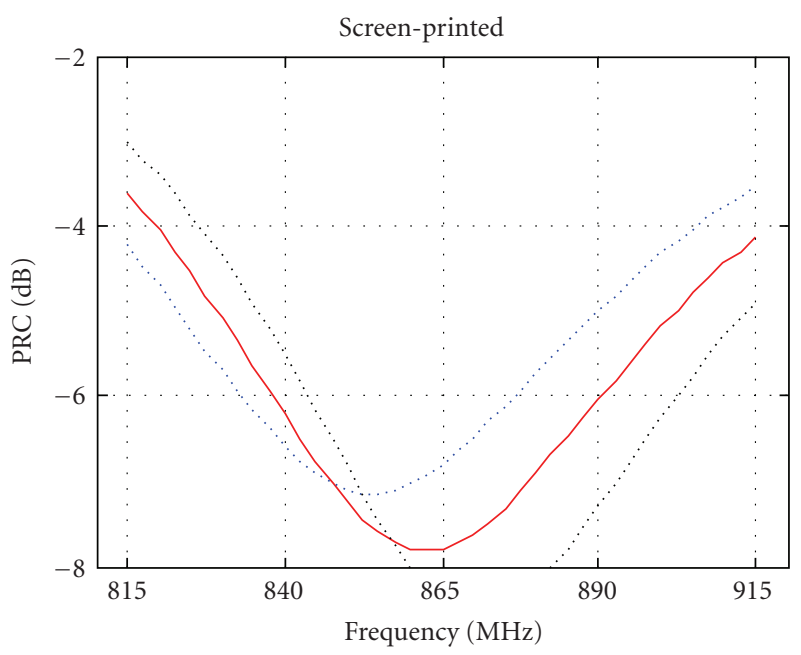

(d)

FIgURE 6: Calculated PRC's according to simulated antenna impedances with $-3 \Omega$ (red dashed curve) and $+3 \Omega$ (black dashed curve) tolerances for chip reactance. 


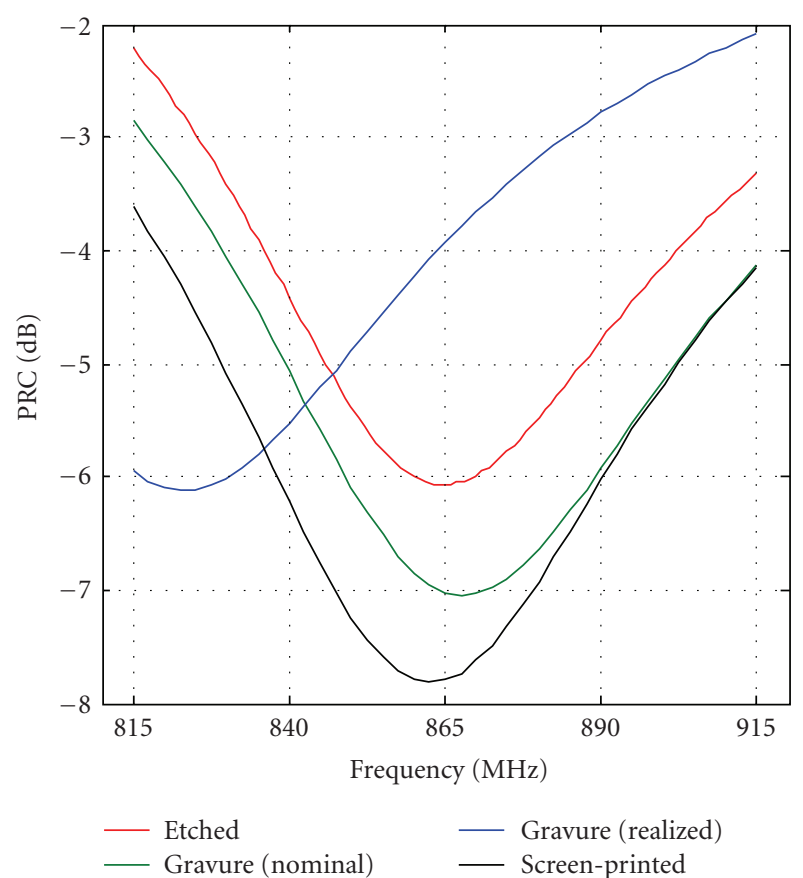

FIGURE 7: PRC's of different antenna models according to the simulated antenna impedances.

seems to be slightly lower than predicted. This might be due to lower than expected strap reactance, as results in Figure 6 suggest.

The measurement results for backscattered signal power in Figure 9 show that at the threshold power, when the IC-chips on the different tags receive approximately equal power, the strength of the responses are almost the same from the etched and screen-printed tags as well as from the commercial Alien Squiggle tag, which was measured as a reference. Response from the gravure-printed tag is about $2 \mathrm{~dB}$ weaker.

Since the manufactured tags are very similar to each other, differences in the measured power levels can be attributed to differences in conductivity and conductor thickness. The commercial Alien Squiggle tag was measured here to provide a frame of reference for the measured values. However, since it is smaller in size, no direct comparison can reasonably be made of its performance against the results from the other tags.

Measured detection range patterns for the fabricated tags are presented in Figure 10. On the left is the orthogonal plane for the dipole axis (H-plane) and on the right is the plane containing the dipole axis (E-plane). The mutual order of the measured detection ranges corresponds with the measured threshold powers, but results in Figure 10 provide yet another way to evaluate the fabricated tags' performance. In addition the detection range patterns show how the radiation pattern of the tag affects its detection range, expectedly the measured patterns follow the shape of dipole radiation pattern. Comparing the obtained results between each other it should be remembered, that the detection range for the Gravure-printed tag is not optimal, since as discussed

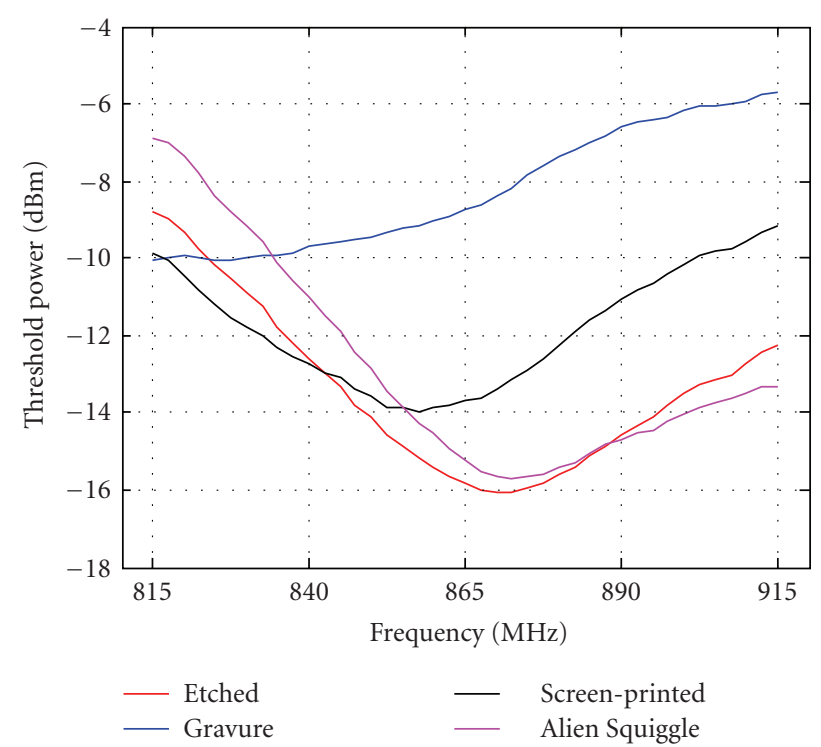

FIGURE 8: Measured threshold power versus frequency.

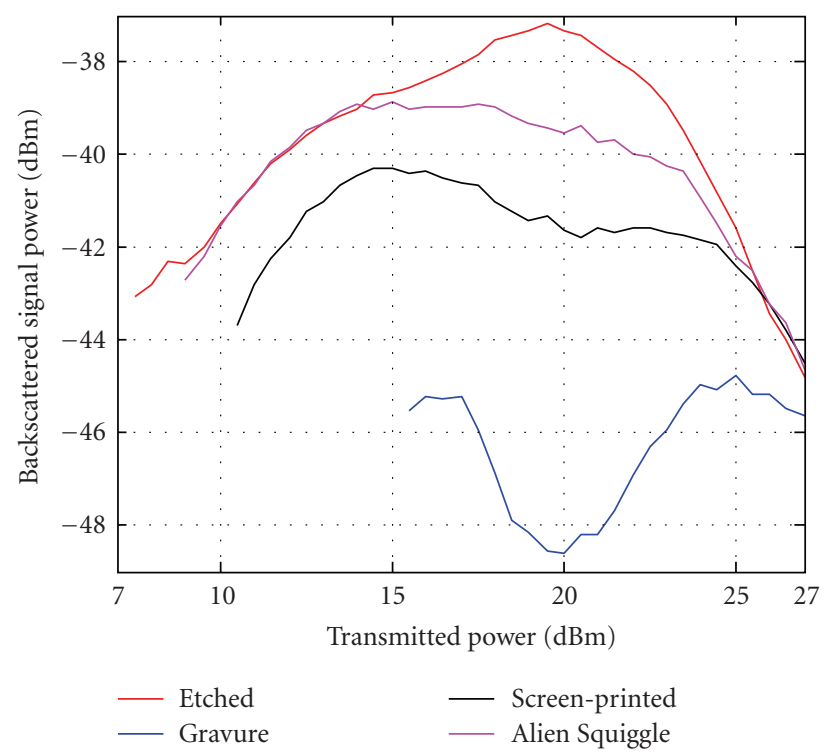

FIGURE 9: Measured backscattered signal power versus transmitted power at $866 \mathrm{MHz}$.

above, the impedance matching of the fabricated gravure printed tag was impaired due to the fabrication process. Nevertheless the measured detection range for the gravureprinted tag demonstrates how the fabrication method may affect the performance of the tag. In this case the maximum achievable range remains around 4 meters, which is quite modest compared to the screen-printed tag. Taking into account that the measured threshold power for the screenprinted tag was $2 \mathrm{~dB}$ higher than for the etched tag (see Figure 8), we conclude that the measured detection range for the screen-printed tag is comparable with the etched tag.

The penetration depth of gravure ink is $8.6 \mu \mathrm{m}$ at $866 \mathrm{MHz}$. This means that the ink layer thickness is less than 


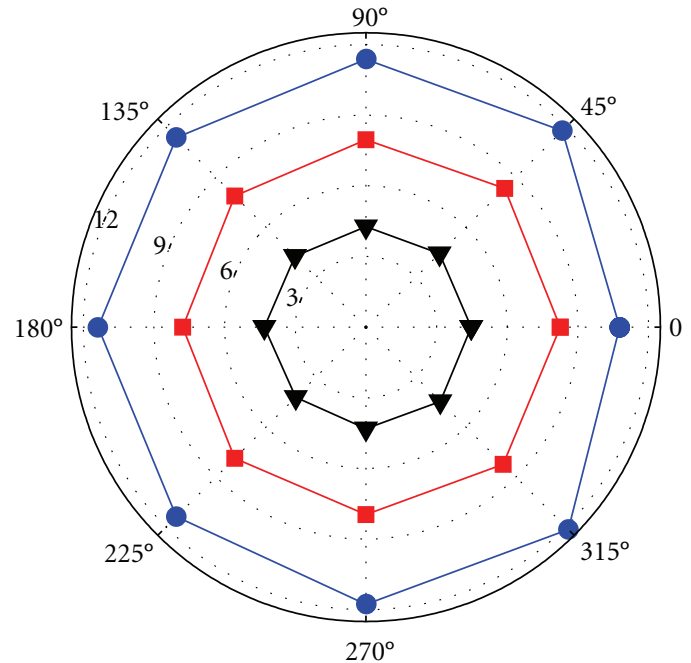

$$
\begin{aligned}
& - \text { Etched } \\
& - \text { Screen-printed } \\
& \neg \text { Gravure-printed }
\end{aligned}
$$

(a)

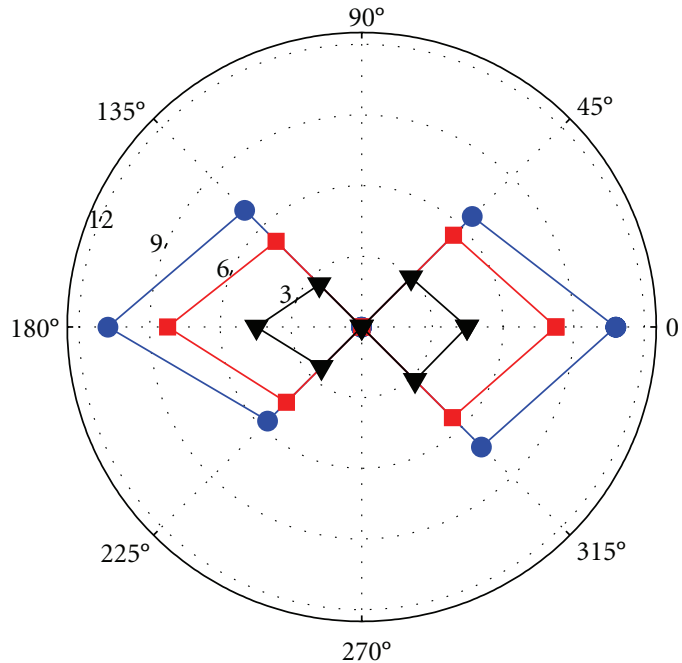

- Etched

- Screen-printed

- Gravure-printed

FIGURE 10: Measured detection ranges $(\mathrm{m})$ at $866 \mathrm{MHz}$ in two orthogonal planes, using $2 \mathrm{~W}$ ERP-power.

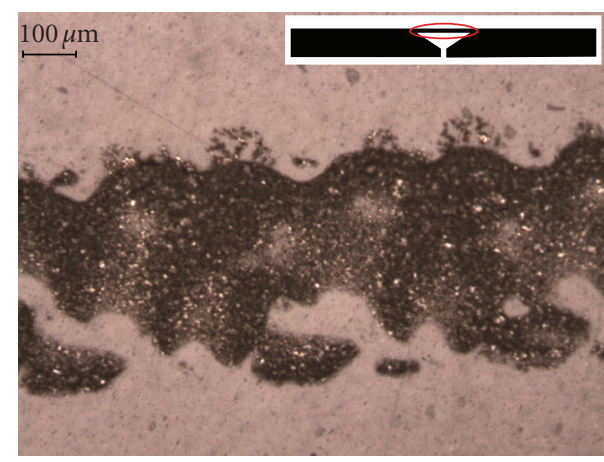

FIGURE 11: Narrow conductive line in antenna, printed with gravure printing.

half of the penetration depth, which affects the performance of the gravure-printed tag by increasing the ohmic losses. As Figure 11 shows, coverage of the ink is not perfect in the narrow part of the antenna and this has probably also affected the measurement results.

The penetration depth of screen printable ink is $15 \mu \mathrm{m}$ at $866 \mathrm{MHz}$ because its conductivity is lower than the conductivity of the gravure printable ink, which means that a thicker layer is required when screen printing is used.

The penetration depth in copper is $2.2 \mu \mathrm{m}$ at $866 \mathrm{MHz}$ and so the $20 \mu \mathrm{m}$ layer is thick in comparison to the penetration depth. The current density has reduced approximately 95\% of its value at the surface after three penetration depths. Therefore it can be assumed that the current flow is not adversely affected by the structure and the ohmic losses remain low [1].
The performance of printed silver ink dipole antennas and copper dipole antennas are investigated, for example, in [15]. Authors found that although silver inks are considerably less conductive, they are competitive when more material is used and can be competitive when using at $1 \mathrm{~mm}$ line widths. Copper dipoles were found to be more efficient than silver ink dipoles of similar dimensions due to the higher conductivity of copper. Authors of [15] also made a simple RFID tag and measured the threshold power, which was higher in case of silver ink tags. Also in [16] silver ink was found to be suitable for fabrication of UHF RFID tags. Printed coil tag antennas were investigated in [17] and they were shown to have read ranges comparable to the copper wire antennas. In [18] RFID bow-tie tag printed with ink jet technique provided good overall performance.

The results we obtained are in accordance with above mentioned results in the references. Printed tags were tuned at the desired frequency and we managed to manufacture a printed tag with almost the same geometry as the copper tag; only a minor change was done to optimize the antenna impedance.

Possible restrictions of printed tags are the maximum ink layer thickness and resolution achieved with different printing methods. Still it is possible to increase the conductivity of the ink, for example, by decreasing the particle size and adding solid content of the ink, but this increases the tag price. Also the printing method has to be selected according the tag model and materials. So it is most probably possible to achieve the same performance as the etched tags, but this increases the costs.

Antenna designing is always a compromise between, among other things, antenna performance, physical dimen-sions of the tag, price, materials (substrate material, 
conductor material, materials nearby during the use of the tag), and manufacturing requirements (process limitations).

\section{Conclusions}

RFID tags can be manufactured using each of the methods investigated in this paper. The performance of the fabricated screen-printed tag is comparable to the copper etched tag with the same conductor thickness. Observed minor difference in their performance is due to the lower conductivity of the screen-printing ink. Decreasing conductor thickness increases losses and thereby decreases efficiency and results to weaker backscatter from the tag.

For a thin conductor layer, the nonuniform distribution in the conducting material in a narrow trace which was included in the matching network of the antenna detuned the antenna significantly impairing its performance. Thus the print quality needs special attention when UHF RFID tags are printed using very thin conducting layers or narrow traces.

Obtained results support the use of printing process as an alternative to etching in manufacturing of RFID tags. Especially printing is an advantageous manufacturing method when the substrate does not tolerate the etching chemicals or tags need to be integrated directly on the product packages.

\section{Acknowledgment}

The financial support of the Finnish Cultural Foundation, Satakunta Regional Fund, and the Ulla Tuominen Foundation is gratefully acknowledged.

\section{References}

[1] EPCglobal, http://www.epcglobalinc.org/tech/freq_reg.

[2] C. A. Balanis, Advanced Engineering Electromagnetics, John Wiley \& Sons, New York, NY, USA, 1989.

[3] W. Zoomer, "Printing technologies make their mark in radio frequency identification," Screenweb, a companion site of the screen printing magazine, 2006.

[4] T. L. Landers, D. B. Brown, E. W. Fant, E. M. Malstrom, and N. M. Schmitt, Electronics Manufacturing Processes, PrenticeHall, Englewood Cliffs, NJ, USA, 1994.

[5] WebelementsTM, http://www.webelements.com/aluminium.

[6] A. Blayo and B. Pineaux, "Printing processes and their potential for RFID printing," in Joint sOc-EUSAI Conference, pp. 27-30, Grenoble, France, October 2005.

[7] J. Costenoble, "Rotary screen printing: the productive solution for HF/UHF RFID labels," SGIA Journal, pp. 7-10, 2005.

[8] S. B. Hoff, Screen Printing: A Contemporary Approach, Delmar, Albany, NY, USA, 1997.

[9] M. Pudas, N. Halonen, P. Granat, and J. Vähäkangas, “Gravure printing of conductive particulate polymer inks on flexible substrates," Progress in Organic Coatings, vol. 54, no. 4, pp. 310-316, 2005.

[10] W. L. Stutzman and G. A. Thiele, Antenna Theory and Design, John Wiley \& Sons, New York, NY, USA, 2nd edition, 1998.

[11] G. Marrocco, "The art of UHF RFID antenna design: impedance-matching and size-reduction techniques," IEEE
Antennas and Propagation Magazine, vol. 50, no. 1, pp. 66-79, 2008.

[12] L. Ukkonen, M. Schaffrath, J. Kataja, L. Sydanheimo, and M. Kivikoski, "Evolutionary RFID tag antenna design for paper industry applications," International Journal of Radio Frequency Identification Technology and Applications, vol. 1, no. 1, pp. 107-122, 2006.

[13] Alien Technology, http://www.alientechnology.com.

[14] Voyantic Ltd., http://www.voyantic.com.

[15] A. Syed, K. Demarest, and D. D. Deavours, "Effects of antenna material on the performance of UHF RFID tags," in IEEE International Conference on RFID, pp. 57-62, Grapevine, Tex, USA, March 2007.

[16] P. V. Nikitin, S. Lam, and K. V. S. Rao, "Low cost silver ink RFID tag antennas," in IEEE Antennas and Propagation Society International Symposium (AP-S '05), vol. 2B, pp. 353-356, July 2005.

[17] S. Y. Y. Leung and D. C. C. Lam, "Geometric and compaction dependence of printed polymer-based RFID tag antenna performance," IEEE Transactions on Electronics Packaging Manufacturing, vol. 31, no. 2, pp. 120-125, 2008.

[18] L. Yang, A. Rida, R. Vyas, and M. M. Tentzeris, "RFID Tag and RF structures on a paper substrate using inkjet-printing," IEEE Transactions on Technology Microwave Theory and Techniques, vol. 55, no. 12, part 2, pp. 2894-2901, 2007. 

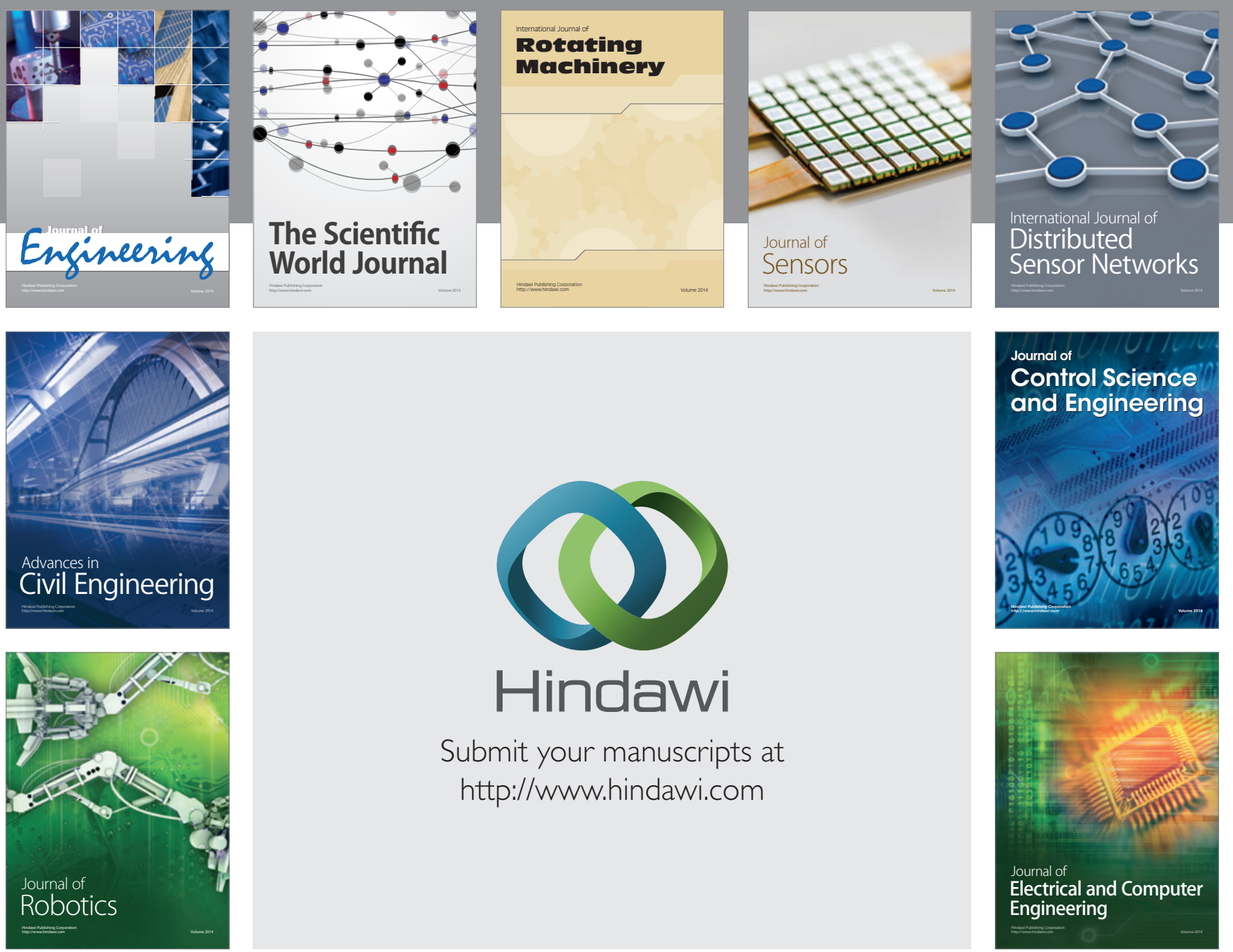

Submit your manuscripts at

http://www.hindawi.com
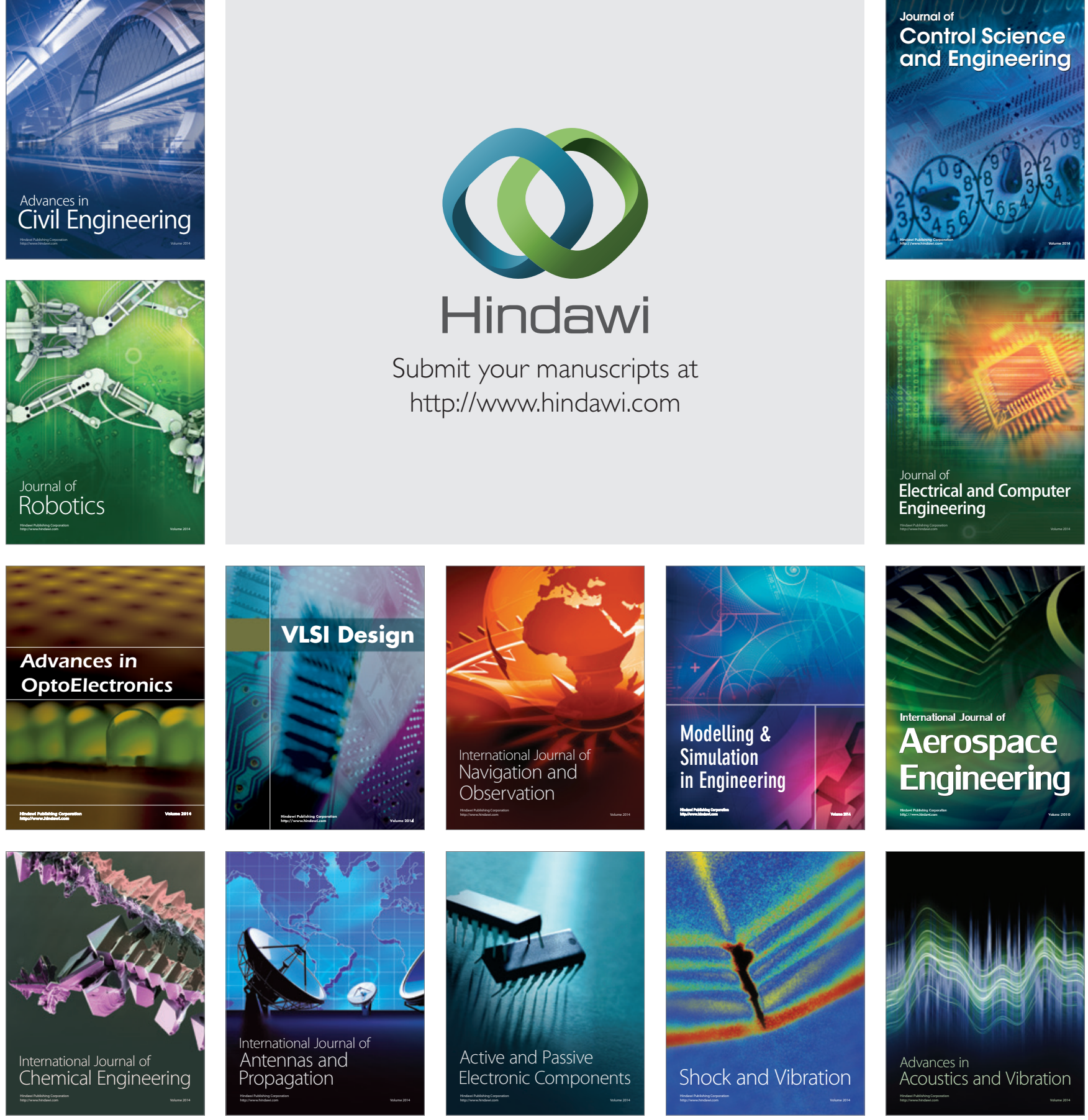